\title{
Prevalence of digital dermatitis in young stock in Alberta, Canada, using pen walks
}

\author{
C. Jacobs, ${ }^{1}$ K. Orsel, and H. W. Barkema \\ Department of Production Animal Health, Faculty of Veterinary Medicine, University of Calgary, Calgary, Alberta, Canada T2N 4N1
}

\begin{abstract}
Digital dermatitis (DD), an infectious bacterial foot lesion prevalent in dairy cattle worldwide, reduces both animal welfare and production. This disease was recently identified in replacement dairy heifers, with implications including increased risk of DD and decreased milk production in first lactation, poor reproductive performance, and altered hoof conformation. Therefore, a simple and effective method is needed to identify DD in young stock and to determine risk factors for DD in this group so that effective control strategies can be implemented. The objectives of this study were to (1) determine prevalence of DD in young stock (based on pen walks); and (2) identify potential risk factors for DD in young stock. A cross-sectional study was conducted on 28 dairy farms in Alberta, Canada; pen walks were used to identify DD (present/absent) on the hind feet of group-housed, young dairy stock. A subset of 583 young stock on 5 farms were selected for chute inspection of feet to determine the accuracy of pen walks for DD detection. Pen walks as a means of identifying DD lesions on the hind feet in young stock had sensitivity and specificity at the animal level of 65 and $98 \%$, with positive and negative predictive values of 94 and $83 \%$, respectively, at a prevalence of $37 \%$. At the foot level, pen walks had sensitivity and specificity of 62 and $98 \%$, respectively, with positive and negative predictive values of 92 and $88 \%$, respectively, at a prevalence of $26 \%$. Pen walks identified DD in 79 [2.9\%; $95 \%$ confidence interval $(95 \% \mathrm{CI}): 2.3-3.6 \%]$ of $2,815$ young stock on 11 (39\%; $95 \%$ CI: $22-59 \%)$ of 28 farms, with all 79 DD-positive young stock $\geq 309 \mathrm{~d}$ of age. Apparent within-herd prevalence estimates ranged from 0 to $9.3 \%$, with a mean of $1.4 \%$. True within-herd prevalence of DD in young stock, calculated using the sensitivity and specificity of the pen walks, ranged from 0 to $12.6 \%$, with a mean of $1.4 \%$. On the 11 DD-positive farms, the proportion of young stock $>12$ mo of age
\end{abstract}

Received April 18, 2017.

Accepted July 25, 2017.

${ }^{1}$ Corresponding author: jacobs.casey@gmail.com with DD lesions was 9.9\% (95\% CI: 7.8-12.0\%). Multilevel logistic regression was used to assess associations with potential risk factors for DD lesions, including age, leg cleanliness, and lactating herd DD prevalence. Presence of DD in young stock increased as their age increased and was associated with increased prevalence of DD in the lactating herd. Pen walks can be used to identify specific young stock with DD or groups where management practices can be implemented to prevent disease proliferation and transmission.

Key words: digital dermatitis, young stock, heifer, pen walk, prevalence

\section{INTRODUCTION}

Digital dermatitis (DD) is an infectious bacterial foot disease that can reduce both welfare and production of dairy cattle. It is the most prevalent infectious foot lesion affecting lactating dairy cattle in Canada and other developed countries worldwide, with up to $92 \%$ of herds affected and within-herd prevalence ranging from 0 to $74 \%$ (Somers et al., 2005; Holzhauer et al., 2006; Cramer et al., 2008; Solano et al., 2016). Digital dermatitis is a complicated multifactorial disease involving multiple bacterial species and susceptibility is affected by several farm- and animal-level factors. Farm factors associated with higher prevalence of DD include housing indoors (vs. pasture; (Read and Walker, 1998; Wells et al., 1999; Somers et al., 2005; Onyiro et al., 2008) and consequent increased standing time and contact with manure slurry (Laven, 1999; Refaai et al., 2013); poor herd-level leg cleanliness (Relun et al., 2013); poor biosecurity (Rodríguez-Lainz et al., 1996, 1999; Wells et al., 1999); and large herd size (Rodríguez-Lainz et al., 1996; Wells et al., 1999; Solano et al., 2016).

Current DD management practices and research focus on the lactating herd and include herd-level prevention strategies such as footbathing (Laven and Logue, 2006; Nuss, 2006; Döpfer et al., 2012) and hoof trimming (Somers et al., 2005; Holzhauer et al., 2006; Relun et al., 2013), as well as individual-animal topical treatment (Laven and Logue, 2006), based on the assumption that DD can be effectively controlled by focus- 
ing on lactating cows. Additionally, accurate, routine detection and control of DD is easier in lactating cows, because of facilities designed to access hoof trimming chutes and utilize footbaths, as well as the possibility of foot inspection in the milking parlor (Relun et al., 2011; Stokes et al., 2012; Solano et al., 2017a). Regardless, herd-level lactating prevalence is still high, suggesting that current management strategies are suboptimal.

Due to the increased risk of DD in first-lactation cattle, the potential role of young dairy stock in withinherd DD dynamics has been emphasized (Laven and Logue, 2007; Holzhauer et al., 2012; Solano et al., 2016), despite a paucity of evidence. Presence of DD in young stock has been associated with increased risk of DD after calving (Laven and Logue, 2007; Holzhauer et al., 2012) as well as decreased first-lactation milk production, lower conception at first service, increased number of days not pregnant (Gomez et al., 2015b), and changes in hoof conformation (Gomez et al., 2015a). A Danish study describing foot lesions and subsequent lameness before and after calving included a sample of 138 pre-calf heifers from 5 farms, 4 of which had DD in their young stock, with a mean prevalence of $15 \%$ (Capion et al., 2009). After calving, the prevalence of DD in this sample peaked at $39 \%$ within the first 100 DIM. In the Netherlands, an intervention study of 644 heifers from 10 farms reported a DD prevalence of $24 \%$ in young stock housed in cubicles and $17 \%$ in young stock housed on pasture (Holzhauer et al., 2012). However, further reports of prevalence in young stock or its implications on DD dynamics in the lactating herd are limited.

The paucity of evidence for young stock may be due to a lack of accurate DD detection due to inadequate facilities and infrequent handling. These factors further complicate implementation of control methods; for example, routine footbathing or topical treatment. Before developing and implementing adequate control practices for dairy young stock, it is essential to establish a method to easily detect DD, determine the prevalence of DD in these cattle, and identify potential risk factors for DD lesions. The objectives of this study were to estimate DD prevalence in young stock on dairy farms in Alberta, Canada, and to describe and identify potential risk factors for DD-affected young stock. Pen walks were assessed as a method to detect DD in young stock and used to estimate on-farm prevalence.

\section{MATERIALS AND METHODS}

\section{Herds}

Participating farms were selected from a pool of farms in Alberta, Canada, that had previously participated in an evaluation of cow comfort, lameness, and longevity (Morabito et al., 2017). These farms met the following criteria: DHI participant, $\geq 60$ lactating Holstein-Friesian cows, lactating cows housed in a freestall facility with $\leq 2 \mathrm{~h} / \mathrm{d}$ of pasture access, and milked in a parlor. Prevalence of DD in the adult herd was not a selection or inclusion criterion. Data collection occurred between March 25 and September 21, 2015. All methods were approved by the Animal Care Committee (AC14-0216) and Research Ethics Boards (REB14-2120) of the University of Calgary (Calgary, AB, Canada).

\section{DD Lesion Assessment}

Pen Walks. A single observer (CJ) walked through pens where cattle were housed, observing the hind feet of all group-housed female dairy young stock while they were free-roaming or in headlocks. Because young stock were assessed before the lactating herd, the observer was blind to the DD status of the lactating herd. Digital dermatitis was scored dichotomously as present or absent for each hind foot, based on the following signs associated with various DD lesion stages (Döpfer et al., 1997; Berry et al., 2012) observed between heel bulbs: inflammation (difficulty in observing the cleft between the heel bulbs), scab-like tissue, proliferative or hyperkeratotic growth, or red, ulcerative lesions. Absence of all of these signs was indicative of absence of DD (Figure 1a), whereas presence of one or more signs was recorded as presence of DD (Figure 1b, c). Additionally, cleanliness of both hind legs was scored based on Cook (2006), as adapted and described by Solano et al. (2015). In short, cleanliness on the lateral lower hind legs from the coronary band to the middle of the tarsal joint was scored from 1 to 4 according to level of contamination: $1=$ fresh manure at $\leq 50 \% ; 2$ $=$ fresh manure at $>50 \% ; 3=$ dried caked and fresh manure at $\geq 50 \%$; and $4=$ entire legs with dried, caked manure. Groups of cattle were excluded from pen walks if they were housed off property, were at pasture, or conditions were unsafe (e.g., presence of an aggressive bull or cattle were unapproachable).

Trimming Chute Inspection. The accuracy of scoring young stock for DD using pen walks was determined by additional inspection in a hoof-trimming chute. Cattle from 5 participating farms (583 young stock) were selected based on DD being detected on the farm during preliminary pen walks, hoof trimmer availability, and adequate barn design layout to facilitate animal movement and placement of a hoof-trimming chute. Pen walk DD scoring of hind feet was completed on the day of chute inspection (before inspection in the hoof trimming chute) and scored dichotomously as present or absent. 
In the chute, hind feet were cleaned using a paper or cloth towel and scored using the M-stage system (Döpfer et al., 1997; Berry et al., 2012) where M0 is defined as normal digital skin with no evidence of dermatitis; M1 is a small $(<2 \mathrm{~cm}$ in diameter), circumscribed, red-togray epithelial defect; M2 is an ulcerative active lesion, $\geq 2 \mathrm{~cm}$ in diameter with a red-gray surface; M3 (healing stage) occurs after an M2 lesion and is characterized by a firm and scab-like surface; M4 (chronic stage) is a lesion surface raised with brown or black tissue, hyperkeratotic, scaly, or proliferative; and M4.1 is small, red, circumscribed lesions within the boundaries of an existing M4 lesion. Lesions observed in the interdigital space during trimming chute inspection were not recorded. A single observer (CJ) scored feet in both the pen and the hoof trimming chute and pen walk scores and cattle identities were kept separate from chute scores to limit observer bias.

Pen walk scores from the day of chute inspection were compared with M-stages scored in the chute to determine sensitivity (Se), specificity (Sp), and positive and negative predictive values (PPV and NPV, respectively) of various combinations of M-stages detected during pen walks.

Parlor Inspection. On 26 of 28 participating farms (1 farm excluded due to DHI milk recording that day and 1 farm not having a working parlor hose), all lactating cows were scored for DD in the milking parlor by a single observer (CJ), based on the system outlined by Solano et al. (2017a). In summary, hind feet of cows were cleaned with a parlor hose and scored using the M-stage system (Döpfer et al., 1997; Berry et al., 2012) with the use of a mirror device (a mirror glued to a kitchen spatula) and a bright headlamp (Solano et al., 2017a).

\section{Statistical Analyses}

Data Management. Data were entered into Excel (Microsoft Corp., Redmond, WA) and all statistical analyses were done using Stata 13.1 (StataCorp, College Station, TX). For all analyses, $P<0.05$ was considered significant. Descriptive statistics (mean, range, and 95\% CI) were calculated for herd-level characteristics. Housing characteristics were described as the proportion of farms and young stock housed in each setting. For cattle-level outcomes, young stock were scored as DD present if DD was present in $\geq 1$ hind foot during a pen walk.

Test Accuracy and Prevalence Estimation. Accuracy of pen walks in detecting DD lesions was analyzed using both the animal and the foot as the statistical unit. For both levels, the analyses were based on comparing the absent/present DD score from pen walks with the M-stage scores from the trimming chute, using the trimming chute inspection as the reference category. At the animal level, the trimming chute inspection score used as the reference was according to a.

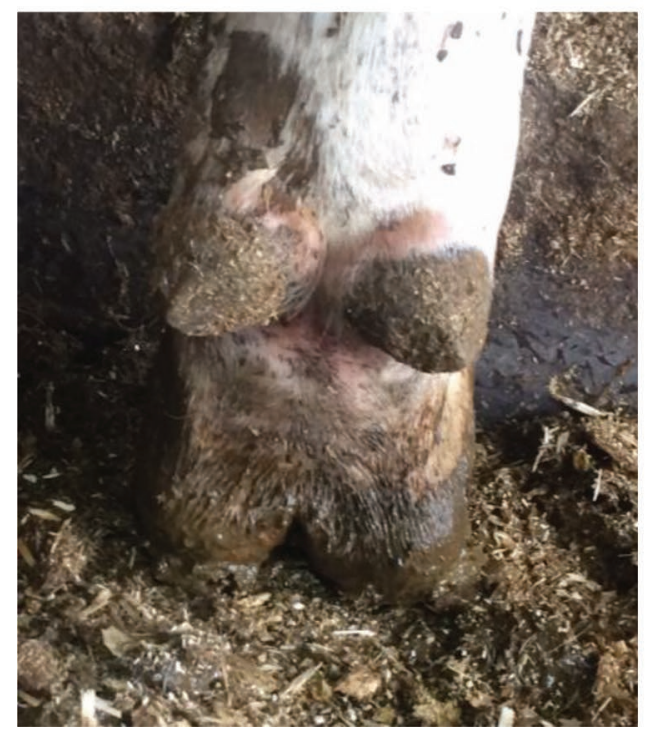

b.

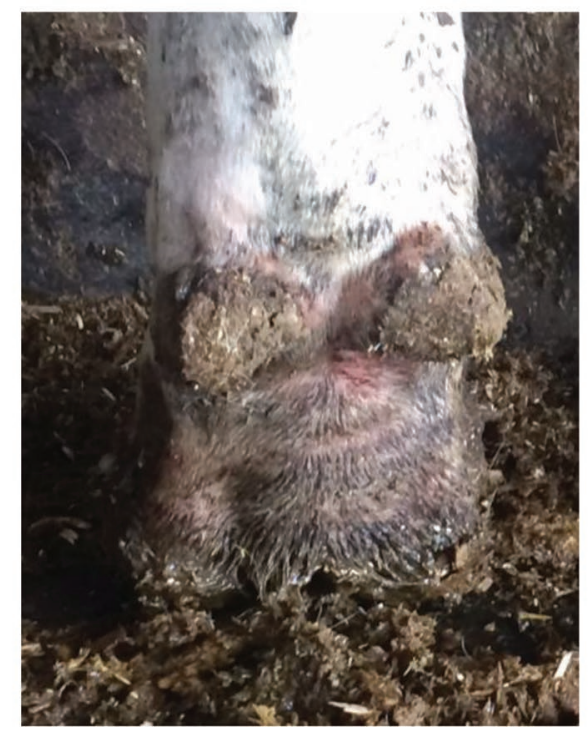

c.

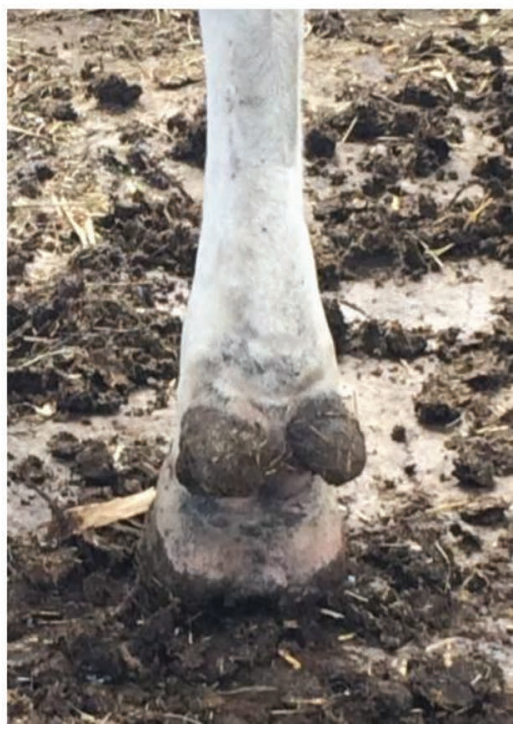

Figure 1. Images of feet scored as (a) digital dermatitis (DD) absent, and (b, c) DD present. The DD-positive feet were scored according to the presence of one or more of the following characteristics observed between the heel bulbs: inflammation (difficulty in observing the cleft between the heel bulbs), scab-like tissue, proliferative or hyperkeratotic growth, or red, ulcerative lesions. Absence of all of these characteristics was indicative of DD-negative feet. Color version available online. 
Table 1. Herd characteristics for the 28 participating dairy farms in Alberta, Canada

\begin{tabular}{lccc}
\hline Characteristic & Mean & Range & $95 \%$ CI \\
\hline Lactating herd size $^{1}$ & 141 & $70-320$ & $118-165$ \\
305-d production (kg) & 9,672 & $7,246-11,177$ & $9,344-10,000$ \\
No. of young stock scored & \\
Age at first calving (mo) & 98 & $23-190$ & $82-114$ \\
No. of young stock pens scored per farm & 26.4 & $23.2-30.4$ & $25.6-27.2$ \\
No. of young stock per pen & 4.4 & $1-12$ & $4.1-4.8$ \\
Young stock age span per pen (d) & 14.8 & $1-90$ & $13.1-16.5$ \\
${ }^{1}$ Lactating herd included all milking cattle (dry cattle excluded) present on day of observation. \\
${ }^{2}$ Young stock scored were all group-housed, on property, dairy young stock; DD was scored on hind feet as \\
present/absent.
\end{tabular}

the hierarchy M2 > M4.1 > M1 > M4 > M3 (Relun et al., 2011; Gomez et al., 2014). For example, if an animal had an M4.1 lesion in one foot and an M1 lesion in the other hind foot, the animal was classified as M4.1. Sensitivity, Sp, PPV, and NPV were calculated at foot and animal level for the absence (M0) or presence of DD using various clinically relevant combinations (M1 to M4.1 inclusive or M2 to M4.1 inclusive) to optimize Se and Sp. Apparent prevalence and accuracy estimates were used to calculate true prevalence of DD (M1 to M4.1 inclusive; Dohoo et al., 2003).

Risk Factor Analysis. Young stock were scored as DD present if DD was present in $\geq 1$ hind foot during a pen walk. Young stock-level characteristics included leg cleanliness [collapsed dichotomously into clean (scores 1 and 2) vs. dirty (scores 3 and 4), due to the low frequency of scores 1 and 4 using the score of the dirtiest leg] and age (in months). If $>1$ lesion was observed on the same foot during trimming chute inspections, the most clinically relevant $\mathrm{M}$-stage was recorded according to M2 > M4.1 > M1 > M4 > M3 (Relun et al., 2011; Gomez et al., 2014).

Herd-level prevalence of DD (M1 to M4.1) in the lactating herd was treated as a farm-level risk factor. Age in months and leg cleanliness were treated as animallevel risk factors. Correlations between animal-level apparent DD prevalence (presence/absence) in young stock and lactating cattle DD prevalence (M1 to M4.1) were estimated using correlation coefficients (r) and coefficients of determination $\left(\mathrm{R}^{2}\right)$.

Univariate analyses were performed to assess associations between DD in young stock and age in months, cleanliness, and lactating DD prevalence. Multilevel regression models were constructed, including all predictor variables significant at $P>0.25$ in the univariate analysis and potential interactions. A backward elimination process was used, with variables significant at $P<0.05$ retained in the final model. Additionally, if confounding was present and removal of any variable resulted in at least a $30 \%$ change in the estimate of another predictor, that variable was also retained in the final model. Farm and pen were included as random effects; however, after removal of insignificant predictors, the variance of pen random effects was close to zero. Inclusion of the pen random effects term did not affect regression coefficient estimates or the associated error in any meaningful way, so it was removed from the model.

\section{RESULTS}

\section{Herd Characteristics}

A total of 2,815 group-housed female dairy young stock were scored on 28 farms in 190 pens with a mean of 14.8 young stock per pen (Table 1). Average lactating herd size in the 28 participating farms was 148 cows (Table 1) with a mean 305-d milk production of 9,276 kg. Cow-level prevalence of DD (stages M1 to M4.1 inclusive) in the lactating herd ranged from 19 to $84 \%$, with a mean of $42 \%$ and a mean foot-level DD prevalence of $37 \%$ (range 13-65\%). Number of female young stock scored per farm ranged from 23 to 190 with a mean age at first calving of 26.4 mo.

The mean age range (difference between youngest and oldest cattle in the same pen) per pen was $114 \mathrm{~d}$. The majority of farms $(25 / 28 ; 89 \%)$ had young stock that were housed outdoors with a shelter (10 farms; $22 \%$ of young stock), indoors with outdoor access (11 farms; $29 \%$ of young stock), or a combination of both (4 farms; $11 \%$ of young stock; Table 2). Three farms (38\% of young stock) housed young stock solely indoors, 6 farms $(21 \%)$ housed young stock in freestall facilities, and 3 farms (11\%) housed young stock in a facility with access to both freestalls and outdoor access. Nineteen farms $(68 \%)$ housed young stock on bedded packs. Straw was the most common bedding for young stock, used on $93 \%$ of farms and for $68 \%$ of young stock, followed by shavings and dirt pack. Eleven farms (39\%) housed young stock in the same pen as dry cows. 
Table 2. Housing characteristics of farms and young stock $^{1}$ on 28 dairy farms

\begin{tabular}{lcc}
\hline Young stock housing & $\begin{array}{r}\text { No. }(\%) \text { of farms } \\
(\mathrm{n}=28)\end{array}$ & $\begin{array}{c}\text { No. (\%) of young stock } \\
(\mathrm{n}=2,815)\end{array}$ \\
\hline DD present in young stock & $11(39)$ & $79(3)$ \\
Housed with access to outdoors & $13(46)$ & $1,017(36)$ \\
Housed in outdoor pen with shelter & $15(54)$ & $732(26)$ \\
Housed in freestalls & $6(21)$ & $368(13)$ \\
Housed with access to freestalls & $3(11)$ & $199(7)$ \\
Housed in bedding types & & \\
Straw & $26(93)$ & $1,923(68)$ \\
Shavings & $7(25)$ & $298(11)$ \\
Straw and shavings mixed & $1(4)$ & $72(3)$ \\
Dirt & $6(21)$ & $365(13)$ \\
Sand & $1(4)$ & $90(3)$ \\
Rubber mats & $1(4)$ & $65(2)$ \\
Commingled with dry cows & $11(39)$ & $203(7)$ \\
\hline
\end{tabular}

${ }^{1}$ Young stock scored were all group-housed, on property, dairy young stock.

${ }^{2}$ Percentages of farms add to $>100 \%$ due to multiple bedding types or housing facility types occurring on 1 farm in different young stock pens.

Several groups of animals were excluded for being housed off-property or on pasture, or because of unsafe conditions (presence of an untrustworthy bull or unapproachable cattle). Four farms kept young stock in pens with untrustworthy bulls and 2 farms kept pregnant young stock on pasture, and therefore, these groups of cattle were not examined. One farm raised young stock off-property without pasture access until confirmed pregnant, so data were only available for pregnant young stock; however, none of these young stock had DD lesions.

\section{Accuracy of Pen Walk}

The hind feet of 292 young stock on 5 farms (535 observations) where DD had been previously identified in young stock via pen walks were scored for DD in a hoof-trimming chute. Missing data occurred for 49 observations for various reasons, including inability to score the foot during pen walk $(\mathrm{n}=36)$ or the heifer being released from the chute before scoring the foot $(\mathrm{n}=14)$. The proportion of young stock with any DD lesion (M1 to M4.1 inclusive) as identified in the trimming chute was $37 \%$, with $25.6 \%$ of total hind feet inspected having a DD lesion. Pen walks identified 108 of 292 young stock, with 137 of 535 feet inspected as having DD compared with chute inspections as the reference. Pen walks had Se, Sp, PPV, and NPV for identifying M1-M4.1 inclusive lesions at the animal level of $65,98,94$, and $83 \%$, respectively. At the foot-level, pen walks had Se, Sp, PPV, and NPV for identifying M1-M4.1 inclusive lesions of $62,98,92$, and $88 \%$, respectively (Table 3 ). However, $77 \%$ of M1 lesions at the foot level were misclassified as DD absent at the foot level. Therefore, accuracy of pen walks for detecting combined M2-M4.1 lesions was determined as Se, Sp, PPV, and NPV of $70,97,93$, and $87 \%$, respectively, at the animal level, and $74,97,85$, and $94 \%$, respectively, at the foot level (Table 3). Pen walks for identifying specific lesion stages at the animal level had a sensitivity of $22,84,78$, and $56 \%$ for M1, M2, M4, and M4.1 lesions, respectively, and a specificity of $74,90,76$, and $76 \%$ for the same. Pen walks for identifying specific lesion stages in feet had a sensitivity of $23,80,70$, and $54 \%$ for M1, M2, M4, and M4.1 lesions, respectively, and specificities of $83,92,85$, and $84 \%$ for the same (Table 3).

\section{Young Stock DD Prevalence}

All Herds. Pen walks identified 79 (2.9\%; 95\% CI: $2.3-3.6 \%$ ) of 2,815 young stock ( $3 \mathrm{~d}$ of age until calving) as having DD on 11 (39\%; 95\% CI: 22-59\%) of the 28 farms (Table 2), resulting in an overall apparent herd-level prevalence of 39\%. Apparent DD foot-level prevalence among all 28 herds ranged from 0 to $9.3 \%$, with a mean of $1.4 \%$ (Figure 2). True within-herd young stock foot-level prevalence for DD M1-M4.1 inclusive lesions ranged from 0 to $12.6 \%$, with a mean of $1.4 \%$, and true within-herd young stock foot-level prevalence of M2-M4.1 inclusive lesions ranged from 0 to $8.5 \%$ with a mean of $0.6 \%$ for all farms.

DD-Positive Herds. The mean within-herd prevalence of the 11 herds with DD-positive young stock was 6.1\% (95\% CI: 4.9-7.6\%). The proportion of young stock with DD $>12$ mo of age was $11 \%$ (95\% CI: $8.9-$ $13.5 \%$ ). Of the 79 young stock identified as having DD in at least 1 hind foot, $24 \%$ were affected in both hind feet. Apparent DD foot-level prevalence within the 11 positive herds ranged from 0.4 to $9.3 \%$, with a mean of 


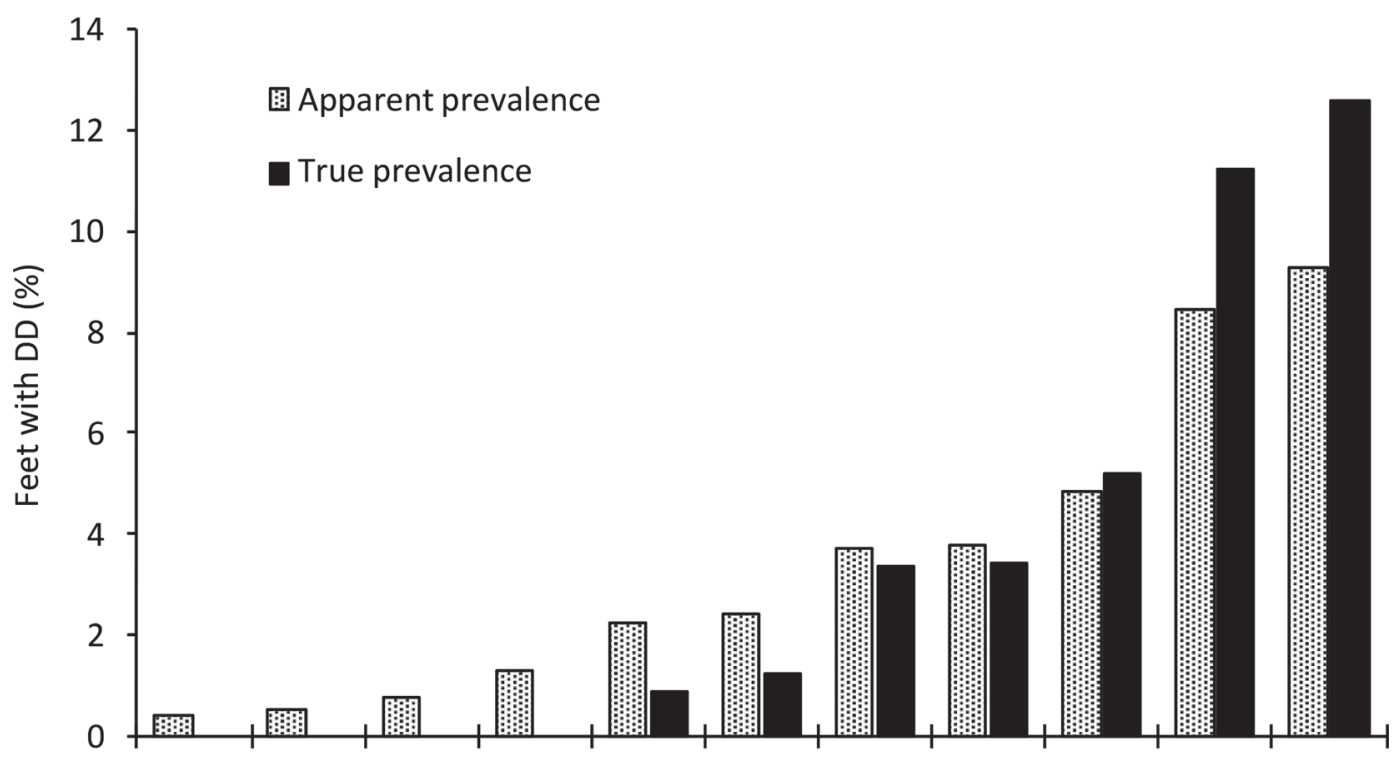

Farms

Figure 2. Apparent pen walk prevalence and true prevalence estimates of foot-level digital dermatitis (DD; stages M1 to M4.1 inclusive) identified in young stock, using a trimming chute as the gold standard for DD detection.

3.4\%. True within-herd young stock foot-level prevalence for DD lesions M1-M4.1 inclusive and M2-M4.1 inclusive ranged from 0 to $12.6 \%$ with a mean of $5.4 \%$ and 0 to $8.5 \%$ with a mean of $3.9 \%$, respectively.

\section{Risk Factors}

Age of young stock ranged from 3 to $875 \mathrm{~d}$, with a mean age of $375 \mathrm{~d}$, whereas mean age of the 79 young

Table 3. Test characteristics (95\% CI in parentheses) for scoring digital dermatitis (DD; presence vs. absence) using pen walks for each DD stage and with scoring in the trimming chute as the gold standard ( $\mathrm{n}=292$ young stock, 535 feet)

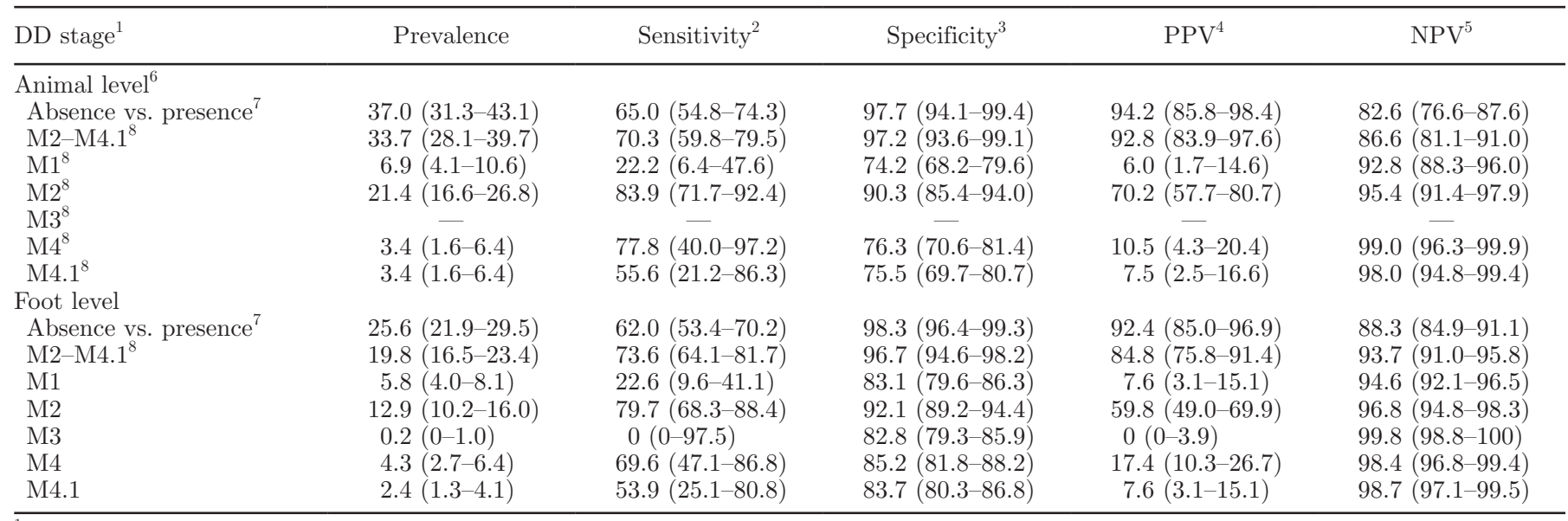

${ }^{1}$ According to Berry et al. (2012).

${ }^{2}$ Proportion of feet/cattle affected with an M-stage of DD identified as DD present by pen walks.

${ }^{3}$ Proportion of feet/cattle not affected with an M-stage of DD identified as DD absent by pen walks.

${ }^{4}$ Positive predictive value $=$ probability that given DD presence was identified by pen walks, the foot/animal is affected by an M-stage .

${ }^{5}$ Negative predictive value $=$ probability that given DD absence identified by pen walks, the foot/animal is not affected by an M-stage.

${ }^{6}$ Presence of DD in cattle with specific M-stage based on the hierarchy M2 > M4.1 > M1 > M4 > M3 (Relun et al., 2011); no observations for M3.

${ }^{7}$ Absence (M0) vs. presence of M1 to M4.1.

${ }^{8}$ Absence (M0 or M1) vs. presence of M2 to M4.1. 


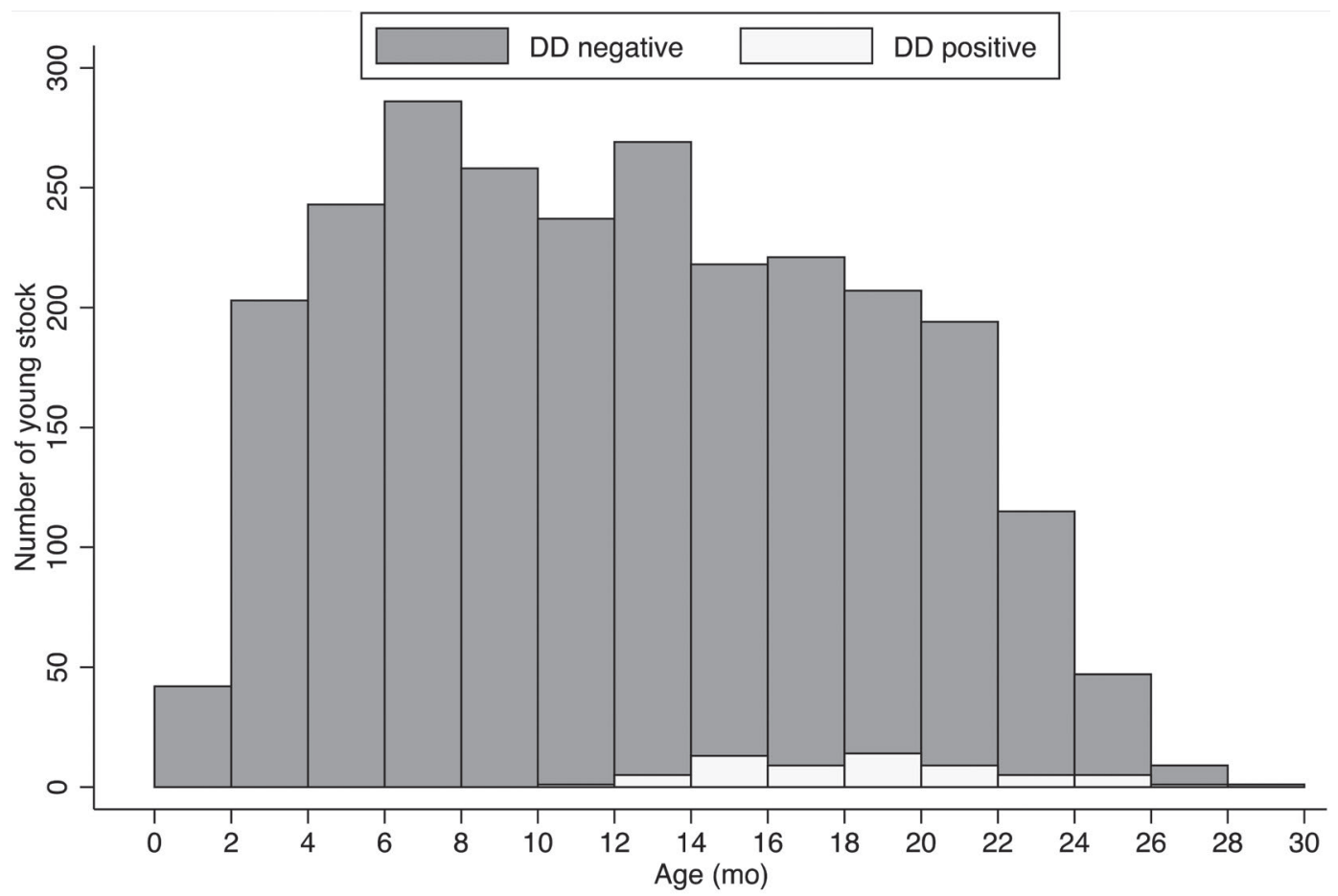

Figure 3. Distribution of age (mo) of 2,550 young stock scored for digital dermatitis (DD) using pen walks, with 79 young stock detected as having DD in at least 1 foot (DD-positive was defined as DD present in at least 1 hind foot as identified by pen walks).

stock identified as having DD was $563 \mathrm{~d}(\mathrm{SEM}=14.1)$ with the youngest identified with DD being $309 \mathrm{~d}$ (Figure 3). Age was missing for $265(9 \%)$ of 2,815 cattle; however, age data were complete for all 79 young stock identified with DD.

On farms where DD was present in young stock, mean lactating herd DD prevalence (M1-M4.1) was $50.4 \%$ (95\% CI: 38.7-62.0\%) compared with a mean of $37.3 \%$ (95\% CI: $29.3-45.2 \%$ ) on farms where DD was not present in young stock (Table 4). The correlation coefficient between the apparent young stock herd-level DD prevalence (presence/absence) and the cow-level prevalence of DD (M1-M4.1) on the 11/28 farms where DD was identified in young stock was $0.73(P=0.001$; Figure 4).

Only young stock age (in months) and lactating cow DD prevalence were included in the final model. Leg cleanliness was not associated with DD presence in

Table 4. Lactating herd digital dermatitis (DD) prevalence (\%, 95\% CI in parentheses) on farms where DD was $(\mathrm{n}=11)$ or was not $(\mathrm{n}=17)$ detected in young stock $^{1}$ during pen walks

\begin{tabular}{lcc}
\hline Item & $\begin{array}{c}\text { DD detected } \\
\text { in young stock }\end{array}$ & $\begin{array}{c}\text { No DD detected } \\
\text { in young stock }\end{array}$ \\
\hline $\begin{array}{l}\text { Lactating herd DD prevalence }(\%)^{2,3,4} \\
\text { M stage }\end{array}$ & $50.4(38.7-62.0)$ & $37.3(29.3-45.2)$ \\
M0 & $49.6(38.0-61.3)$ & $62.7(54.8-70.7)$ \\
M1 & $5.6(2.2-9.0)$ & $2.7(0.6-4.8)$ \\
M2 & $4.3(2.2-6.4)$ & $2.4(1.4-3.4)$ \\
M3 & $9.4(3.7-15.2)$ & $11.4(6.5-16.2)$ \\
M4 & $25.1(16.3-33.9)$ & $15.4(6.7-24.0)$ \\
M4.1 & $3.9(1.5-6.2)$ & $3.3(1.1-5.5)$ \\
\hline
\end{tabular}

${ }^{1}$ Young stock scored were all group-housed, on property, dairy young stock; DD was scored on the hind feet as present/absent.

${ }^{2}$ Lactating herd included all milking cattle (dry cattle excluded) present on day of observation.

${ }^{3}$ Two farms were missing lactating herd DD data (1 due to DHI herd testing on the day of visit and 1 due to the lack of a parlor hose to clean feet).

${ }^{4}$ Cow level; a cow with $>1$ DD lesion was scored according to the most clinically relevant M-stage, as follows: $\mathrm{M} 2>\mathrm{M} 4.1>\mathrm{M} 1>\mathrm{M} 4>\mathrm{M} 3>\mathrm{M} 0$. 
Table 5. Final multilevel logistic regression model for digital dermatitis (DD) lesions in young stock $(\mathrm{n}=2,550)$ on $26^{1}$ dairy farms

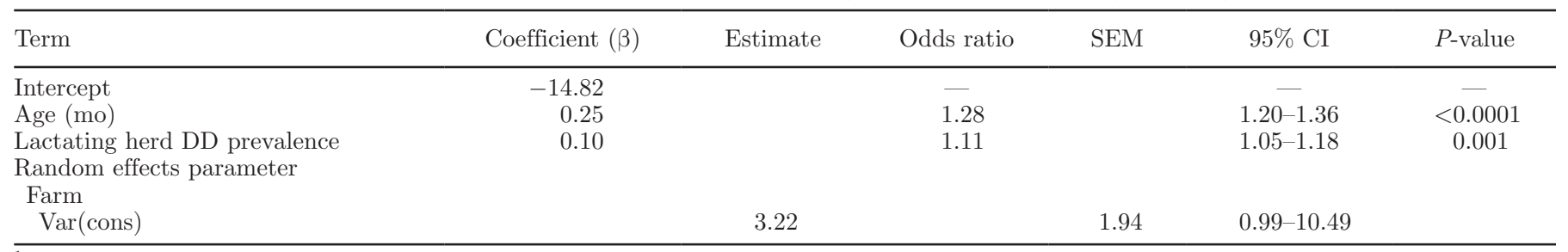

${ }^{1}$ Two farms were excluded because lactating herd was not scored for DD.

young stock; of the 2,658 uninfected animals, 421 (16\%) had cleanliness scores of 3 or 4 compared with 23 of 79 ( $29 \%)$ young stock with DD. Each 1-mo increase in age resulted in a 1.28 (95\% CI: $1.20-1.36)$ increase in odds of DD in young stock. Additionally, each 1 percentage point increase in lactating cow DD prevalence was associated with a 1.11 (95\% CI: 1.05-1.18) increase in odds of DD in young stock (Table 5).

\section{DISCUSSION}

This is apparently the first North American report on the prevalence of DD in young dairy cattle and the first to determine the accuracy of pen walks for detecting DD lesions in these cattle compared with M-stage scoring in the trimming chute as a reference. The accuracy of pen walks for detecting presence or absence of lesions is sufficient to use pen walks to identify groups of cattle that require preventative management or treatment. True foot-level DD prevalence in young stock on the 28 farms ranged from 0 to $12.6 \%$, highlighting an unexplored reservoir of DD. Furthermore, the prevalence of

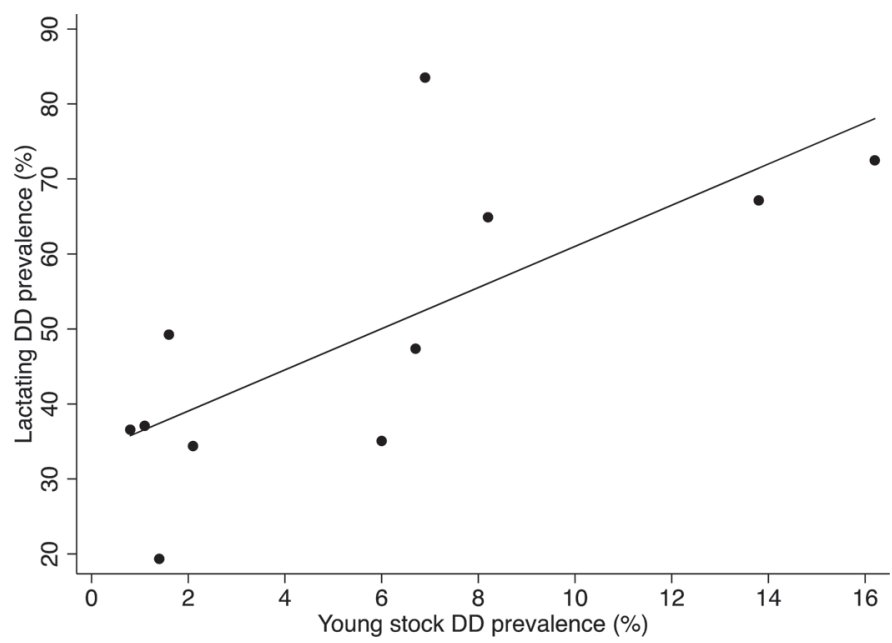

Figure 4. Correlation between apparent lactating herd prevalence and young stock prevalence of digital dermatitis (DD) on 11 Alberta dairy farms where DD was identified in young stock during pen walks. $\mathrm{R}^{2}=0.54$. Total cows scored $=2,782$; total young stock scored $=$ 2,573 .
DD in young stock was associated with increased age and increasing prevalence of DD in the lactating herd.

Overall, pen walks correctly identified DD lesions in $62 \%$ of young stock with M1-M4.1 lesions and $98 \%$ of animals with no lesions (M0). Sensitivity improved to $74 \%$, whereas specificity decreased to $97 \%$ in identifying M2-M4.1 (inclusive) lesions and excluding M1 lesions (misclassification of $77 \%$ of M1 lesions as DD absent was attributed to their being small). Similarly, $93 \%$ of M1 lesions in lactating cows scored in the milking parlor in Solano et al. (2017a) were misclassified compared with those identified in the trimming chute, so this high misclassification was expected. The low sensitivity for detecting M1 lesions would hamper efforts to treat individual animals with early lesions based on pen walk detection; however, the level of accuracy is high enough to incorporate pen walks into DD management programs, which would allow young stock to be screened for preventative DD strategies and to be selected for further inspection and potential treatment in the trimming chute. Data collected during pen walks could be recorded in the mobile Zinpro DD Check application (Zinpro Corp., Eden Prairie, MN) to identify trends in DD prevalence, create treatment lists, predict outbreaks and assist in making management decisions (Tremblay et al., 2016).

Using pen walks, DD was detected on the hind feet of a total of 79 young stock on 11 of $28(39 \%)$ farms, resulting in a mean within-herd true foot-level prevalence estimate of $1.4 \%$ and a mean animal-level prevalence of $2.9 \%$. On farms where DD was identified in young stock, the prevalence of DD in heifers $>12$ mo of age was $11 \%$. These results appeared lower compared with other studies reporting prevalence in young stock. A Danish study reported precalving heifer prevalence of $15 \%$ in 138 heifers selected from 5 herds at 4 mo before calving (Capion et al., 2009), whereas in Wisconsin, foot-level DD prevalence was $21 \%$ in a cohort of 644 heifers from 1 herd at a mean age of $635 \mathrm{~d}$ and $30 \%$ at a mean age of $714 \mathrm{~d}$ (Gomez et al., 2015a). However, in both of those studies, heifers were selected from lactating herds endemic with DD and based on young stock being free of DD at the start of the study. Additionally, 
the 2 studies (Capion et al., 2009; Gomez et al., 2015b) were longitudinal and selected fewer heifers that were closer to calving to determine the association between pre- and postcalving effects of DD lesions, and therefore may not be representative of overall DD prevalence in young stock.

Our study included only group-housed young stock; some cattle or groups of cattle were excluded due to being housed off property or on pasture, or when conditions were unsafe (presence of an untrustworthy bull or unapproachable cattle). The majority of cattle excluded comprised young stock $>1$ yr of age, which is when DD is most prevalent $(9.9 \%$ in young stock $>12$ mo of age on farms where DD was identified in young stock) and therefore true within-herd prevalence may have been underestimated.

The accuracy of pen walks for detecting DD in young stock is likely influenced by hind foot conformation. Compared with older cattle, young stock have an increased foot angle (Boelling and Pollott, 1998) and therefore the typical site (between the heel bulb) is easier to see, thereby facilitating DD detection. Pen walks used in lactating cattle may differ in test characteristics depending on the angle of the foot, which can be exacerbated by prior infection with DD (Gomez et al., 2015a). Unfortunately, pen walks can only easily detect DD lesions present on the typical site on hind feet. In lactating cattle, $94 \%$ of DD lesions occur on the hind feet, with $85 \%$ of DD lesions present at the typical site and $18 \%$ affecting the interdigital space (Solano et al., 2016). In 256 pre-calf heifers selected for trimming, 86 animals were affected with DD, 76 heifers with lesions on the typical site between the heel bulbs and 15 heifers (17\% of those with DD) with lesions present in the interdigital space [Solano et al., 2016; L. Solano, S. Mason, E. A. Pajor (Department of Production Animal Health, University of Calgary, Calgary, Alberta, Canada), S. J. LeBlanc (Department of Population Medicine, University of Guelph, Guelph, Ontario, Canada), unpublished data]. However, as those animals were selected by the producer for foot trimming, this estimate is likely overestimated. Regardless, not having included interdigital DD lesions would result in an overestimation of the sensitivity of pen walks, as young stock with DD lesions in the interdigital space will not be detected. Fortunately, pen walks are a useful tool to identify groups of animals that may be affected by DD so that a more thorough examination can be conducted and preventative control measures can be implemented.

The seemingly high overall DD prevalence in the lactating herd (ranging from 19 to $84 \%$ ) is likely due to reporting a prevalence based on M1-M4.1 inclusive stages. Other reports of DD prevalence in lactating cattle have focused on M1 and M2 stages only (Somers et al., 2003), different scoring systems (Holzhauer et al., 2006), or specific groups of animals (Capion et al., 2012). Multi-farm footbath trials conducted in Alberta, Canada, have reported prevalence of M1-M4.1 lesions ranging between 15 and $86 \%$ (Jacobs et al., 2017; Solano et al., 2017b), similar to this study.

Of risk factors considered, increasing age and increased lactating herd DD prevalence were associated with increased DD presence in young stock. The association with increasing age may be due to closer contact with adult cows and increased exposure to contaminated material and potentially exacerbated by hormonal changes associated with pregnancy. The association between DD presence in young stock and increased lactating herd DD prevalence suggests that introducing DD-affected young stock into the lactating herd may undermine DD control. Furthermore, presence of DD in young stock may contribute to a higher proportion of chronic cases once these young stock are introduced into the lactating herd, especially because DD presence before calving is indicative of a higher risk of DD after calving (Laven and Logue, 2007; Holzhauer et al., 2012). As these lesions heal, there will be an increase in the proportion of lesions that act as the reservoir of disease (M4), which may progress to M4.1 and M2 lesion stages (Döpfer et al., 2012). Alternatively, the association may be due to management of both young stock and lactating cattle having been suboptimal to control DD in both groups. Of the 11 farms where DD was present in young stock, $54 \%$ of the variation in the lactating herd prevalence was explained by variation in prevalence in young stock, highlighting the importance of targeted DD management before calving. Routine screening of young stock for DD should focus on cattle $>12$ mo of age, with prevention strategies aimed at groups younger than the age at which DD is first detected.

Despite evidence of association between leg cleanliness and DD occurrence found in some studies (Relun et al., 2012, 2013; Solano et al., 2017b), we were unable to detect an association in the current study, even when including only farms where DD was detected in young stock. This may be due to the different housing systems (e.g., outdoor, bedded-packs) used for the lactating cows included in the aforementioned studies and the young stock in this study. Additionally, Solano et al. (2017b) determined that leg cleanliness scores were confounded by farm and hypothesized this to be the relationship between high DD prevalence on farms with the dirtiest legs. Both French studies (Relun et al., 2012 , 2013) found herd-level, as opposed to cow-level, leg cleanliness to be associated with DD occurrence.

Although no other risk factors considered (outdoor housing or access, access to freestalls, bedding types, and 
commingling with dry cows) were significant due to the lack of power to detect pen-level predictors, exposure to DD-affected cattle or material is likely important. In an experimental infection trial, negative control animals housed with experimentally infected animals developed DD lesions (Krull et al., 2016). The current study only measured exposure directly (young stock commingled with dry cows); however, young stock housed adjacent to cows, in housing previously containing cows, or sharing boots or equipment between cows and young stock may have diluted apparent effects of exposure. Of the 79 young stock identified with DD, only 9 cattle from 5 farms were commingled with cows. For the remaining 70 cattle, exposure may have occurred indirectly. A total of 27 young stock identified with DD were from 1 farm where young stock were housed in an old milking barn, another farm contained 15 DD-positive young stock housed adjacent to dry cows, and a third farm had 7 young stock identified with DD, including the youngest heifer identified in this study. On the latter farm, these young stock were housed in a barn with an automatic manure scraper that ran from the close-up pen (including young stock and dry cows) and down the length of the barn, including 4 pens housing young stock. It was noteworthy that the 309-d-old heifer with DD was housed in the pen farthest from the close-up pen, emphasizing the potential of indirect exposure.

Other potential risk factors that were not analyzed in the current study due to insufficient power at the herd level included pen cleanliness, bedding material, and commingling with older cows. Cleaning frequency could be a proxy for cleanliness in future studies; however, this could be confounded by exposure if equipment is contaminated by DD-infected cattle. Currently, the amount of environmental contamination or indirect exposure required to result in DD lesion development in susceptible animals is unknown, but contaminated material increases severity of postcalving DD lesions (Laven and Logue, 2007), suggesting that contaminated housing or bedding could be responsible for DD infection. The interval over which infectious material persists in a contaminated environment is also unknown. Future research should focus on preventative strategies in young stock and how this may affect prevalence of DD in lactating cattle. Additionally, the odds of DD infection is higher for primiparous cows than for multiparous cows (Solano et al., 2016), perhaps due to stress associated with calving, lactation, and introduction to the lactating herd. Young stock management should include routine detection for DD lesions, ideally implementing prevention practices before DD is present, maintaining clean equipment and environments to limit contamination, and housing fresh first-lactation cows separately from the lactating herd to limit transmission of DD (Laven and Logue, 2007; Holzhauer et al., 2012).

\section{CONCLUSIONS}

Digital dermatitis was identified in young stock on $39 \%$ of farms, with a mean true within-herd foot level prevalence of $1.4 \%$ (ranging from 0 to $12.6 \%$ ). Increasing age of young stock and lactating herd DD prevalence were associated with increased DD presence in young stock. Young stock may therefore act as a reservoir of DD that can be transmitted to lactating cattle after calving. Pen walks were a simple and noninvasive method of detecting DD lesions in young stock with a relatively high sensitivity and specificity of detecting DD. Therefore, pen walks could identify groups that may require the implementation of preventative and treatment routines to manage DD lesions. Prevention and treatment strategies should be implemented in young stock groups where DD is present to prevent disease proliferation and transmission and improve DD control on dairy farms.

\section{ACKNOWLEDGMENTS}

This study was funded by Alberta Milk (Edmonton, AB, Canada) and Growing Forward 2 Biosecurity Delivery Agent (Edmonton, AB, Canada). The authors thank participating farmers and hoof trimmers Elbert Koster (No Tilt Hooftrimming, Spruceview, AB, Canada) and Rob Geier (Casper Hooftrimming, Olds, AB, Canada). We are especially grateful to Emily Morabito (University of Calgary, Calgary, AB, Canada), Rasia Englebert (Utrecht University, the Netherlands), and Colin Nicholas (University of Calgary, Calgary, AB, Canada) for assisting with data collection. We also convey our appreciation to John Kastelic (University of Calgary, Calgary, AB, Canada) for editing this manuscript.

\section{REFERENCES}

Berry, S. L., D. H. Read, T. R. Famula, A. Mongini, and D. Döpfer. 2012. Long-term observations on the dynamics of bovine digital dermatitis lesions on a California dairy after topical treatment with lincomycin HCl. Vet. J. 193:654-658.

Boelling, D., and G. E. Pollott. 1998. Locomotion, lameness, hoof and leg traits in cattle. II: Genetic relationships and breeding values. Livest. Prod. Sci. 54:205-215.

Capion, N., M. Boye, C. T. Ekstrøm, and T. K. Jensen. 2012. Infection dynamics of digital dermatitis in first-lactation Holstein cows in an infected herd. J. Dairy Sci. 95:6457-6464.

Capion, N., S. M. Thamsborg, and C. Enevoldsen. 2009. Prevalence and severity of foot lesions in Danish Holstein heifers through first lactation. Vet. J. 182:50-58 
Cook, N. B. 2006. Footbath alternatives. Accessed March 15, 2017. http://www.vetmed.wisc.edu/dms/fapm/fapmtools/6lame/ Footbath_Alternatives.pdf.

Cramer, G., K. D. Lissemore, C. L. Guard, K. E. Leslie, and D. F. Kelton. 2008. Herd- and cow-level prevalence of foot lesions in Ontario dairy cattle. J. Dairy Sci. 91:3888-3895.

Dohoo, I., W. Martin, and H. Stryhn. 2003. Veterinary Epidemiologic Research. AVC Inc., Charlottetown, Prince Edward Island, Canada.

Döpfer, D., M. Holzhauer, and M. v. Boven. 2012. The dynamics of digital dermatitis in populations of dairy cattle: Model-based estimates of transition rates and implications for control. Vet. J. 193:648-653.

Döpfer, D., A. Koopmans, F. A. Meijer, I. Szakall, Y. H. Schukken, W. Klee, R. B. Bosma, J. L. Cornelisse, A. J. van Asten, and A. A. ter Huurne. 1997. Histological and bacteriological evaluation of digital dermatitis in cattle, with special reference to spirochaetes and Campylobacter faecalis. Vet. Rec. 140:620-623.

Gomez, A., K. S. Anklam, N. B. Cook, J. Rieman, K. A. Dunbar, K. E. Cooley, M. T. Socha, and D. Döpfer. 2014. Immune response against Treponema spp. and ELISA detection of digital dermatitis. J. Dairy Sci. 97:4864-4875.

Gomez, A., N. B. Cook, J. Rieman, K. A. Dunbar, K. E. Cooley, M. T. Socha, and D. Döpfer. 2015a. The effect of digital dermatitis on hoof conformation. J. Dairy Sci. 98:927-936.

Gomez, A., N. B. Cook, M. T. Socha, and D. Döpfer. 2015b. Firstlactation performance in cows affected by digital dermatitis during the rearing period. J. Dairy Sci. 98:4487-4498.

Holzhauer, M., B. Brummelman, K. Frankena, and T. J. G. M. Lam. 2012. A longitudinal study into the effect of grazing on claw disorders in female calves and young dairy cows. Vet. J. 193:633-638.

Holzhauer, M., C. Hardenberg, C. J. M. Bartels, and K. Frankena 2006. Herd- and cow-level prevalence of digital dermatitis in The Netherlands and associated risk factors. J. Dairy Sci. 89:580-588.

Jacobs, C., K. Orsel, S. Mason, K. Gray, and H. W. Barkema. 2017. Comparison of the efficacy of a commercial footbath product with copper sulfate for the control of digital dermatitis. J. Dairy Sci.100:5628-5641.

Krull, A. C., V. L. Cooper, J. W. Coatney, J. K. Shearer, P. J. Gorden, and P. J. Plummer. 2016. A highly effective protocol for the rapid and consistent induction of digital dermatitis in Holstein calves. PLoS One 11:e0154481.

Laven, R. A. 1999. The environment and digital dermatitis. Cattle Pract. 7:349-354.

Laven, R. A., and D. N. Logue. 2006. Treatment strategies for digital dermatitis for the UK. Vet. J. 171:79-88.

Laven, R. A., and D. N. Logue. 2007. The effect of pre-calving environment on the development of digital dermatitis in first lactation heifers. Vet. J. 174:310-315.

Morabito, E., H. W. Barkema, E. A. Pajor, L. Solano, D. Pellerin, and K. Orsel. 2017. Impacts of changing freestall area on lameness, lying time and leg injuries on dairy farms in Alberta. J. Dairy Sci. 100:6516-6526.

Nuss, K. 2006. Footbaths: The solution to digital dermatitis? Vet. J. 171:11-13

Onyiro, O. M., L. J. Andrews, and S. Brotherstone. 2008. Genetic parameters for digital dermatitis and correlations with locomotion, production, fertility traits, and longevity in Holstein-Friesian dairy cows. J. Dairy Sci. 91:4037-4046.

Read, D. H., and R. L. Walker. 1998. Papillomatous digital dermatitis (footwarts) in California dairy cattle: clinical and gross pathologic findings. J. Vet. Diagn. Invest. 10:67-76.

Refaai, W., M. v. Aert, A. M. A. El-Aal, A. E. Behery, and G. Opsomer. 2013. Infectious diseases causing lameness in cattle with a main emphasis on digital dermatitis (Mortellaro disease). Livest. Sci. 156:53-63.

Relun, A., R. Guatteo, P. Roussel, and N. Bareille. 2011. A simple method to score digital dermatitis in dairy cows in the milking parlor. J. Dairy Sci. 94:5424-5434

Relun, A.. A. Lehebel, N. Bareille, and R. Guatteo. 2012. Effectiveness of different regimens of a collective topical treatment using a solution of copper and zinc chelates in the cure of digital dermatitis in dairy farms under field conditions. J. Dairy Sci. 95:3722-3735.

Relun, A., A. Lehebel, M. Bruggink, N. Bareille, and R. Guatteo. 2013. Estimation of the relative impact of treatment and herd management practices on prevention of digital dermatitis in French dairy herds. Prev. Vet. Med. 110:558-562.

Rodríguez-Lainz, A., D. W. Hird, T. E. Carpenter, and D. H. Read. 1996. Case-control study of papillomatous digital dermatitis in southern California dairy farms. Prev. Vet. Med. 28:117-131.

Rodríguez-Lainz, A., P. Meléndez Retamal, D. W. Hird, D. H. Read, and R. L. Walker. 1999. Farm- and host-level risk factors for papillomatous digital dermatitis in Chilean dairy cattle. Prev. Vet. Med. 42:87-97.

Solano, L., H. W. Barkema, C. Jacobs, and K. Orsel. 2017a. Validation of the M-stage scoring system for digital dermatitis on dairy cows in the milking parlor. J. Dairy Sci. 100:1592-1603.

Solano, L., H. W. Barkema, S. Mason, E. A. Pajor, S. J. LeBlanc, and K. Orsel. 2016. Prevalence and distribution of foot lesions in dairy cattle in Alberta, Canada. J. Dairy Sci. 99:6828-6841.

Solano, L., H. W. Barkema, E. A. Pajor, S. Mason, S. J. LeBlanc, J. C. Zaffino Heyerhoff, C. G. Nash, D. B. Haley, E. Vasseur, D. Pellerin, J. Rushen, A. M. de Passille, and K. Orsel. 2015. Prevalence of lameness and associated risk factors in Canadian Holstein-Friesian cows housed in freestall barns. J. Dairy Sci. 98:6978-6991.

Solano, L., H. W. Barkema, C. Pickel, and K. Orsel. 2017b. Effectiveness of a standardized footbath protocol for prevention of digital dermatitis. J. Dairy Sci. 100:1295-1307.

Somers, J. G. C. J., K. Frankena, E. N. Noordhuizen-Stassen, and J. H. M. Metz. 2003. Prevalence of claw disorders in Dutch dairy cows exposed to several floor systems. J. Dairy Sci. 86:2082-2093.

Somers, J. G. C. J., K. Frankena, E. N. Noordhuizen-Stassen, and J. H. M. Metz. 2005. Risk factors for digital dermatitis in dairy cows kept in cubicle houses in The Netherlands. Prev. Vet. Med. 71:11-21.

Stokes, J. E., K. A. Leach, D. C. J. Main, and H. R. Whay. 2012. The reliability of detecting digital dermatitis in the milking parlour. Vet. J. 193:679-684.

Tremblay, M., T. Bennett, and D. Döpfer. 2016. The DD Check App for prevention and control of digital dermatitis in dairy herds. Prev. Vet. Med. 132:1-13.

Wells, S. J., L. P. Garber, and B. A. Wagner. 1999. Papillomatous digital dermatitis and associated risk factors in US dairy herds. Prev. Vet. Med. 38:11-24. 